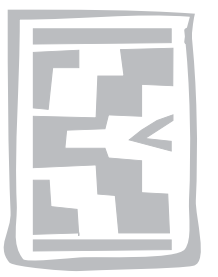

\title{
Cross-sectional estimation of Babesia bovis antibody prevalence in cattle in two contrasting dairying areas in Tanzania
}

\author{
E.S. SWAI ${ }^{1}$, E.D. KARIMURIBO ${ }^{2}$, N.P. FRENCH ${ }^{3}$, N.H. OGDEN ${ }^{4}$, J. FITZPATRICK ${ }^{5}$, \\ D. KAMBARAGE ${ }^{2}$ and M.J. BRYANT6
}

\begin{abstract}
SWAI, E.S., KARIMURIBO, E.D., FRENCH, N.P., OGDEN, N.H., FITZPATRICK, J., KAMBARAGE, D. \& BRYANT, M.J. 2004. Cross sectional estimation of Babesia bovis antibody prevalence in cattle in two contrasting dairy areas in Tanzania. Onderstepoort Journal of Veterinary Research, 71: $211-217$

The crude prevalence of antibodies to Babesia bovis infection in cattle was estimated by serology using indirect ELISA during the period January to April, 1999. Sera were obtained from 1395 dairy cattle (of all ages, sexes and breeds) on smallholder farms, the majority being kept under a zero grazing regime. The crude prevalence of antibodies to Babesia bovis was $6 \%$ for Tanga and $12 \%$ for Iringa. The forces of infection based on the age sero-prevalence profile, were estimated at six for Iringa and four for Tanga per 100 cattle years-risk, respectively. Using random effect logistic regression as the analytical method, the factors (variables) of age, source of animals and geographic location were hypothesised to be associated with sero-positivity of Babesia bovis in the two regions.
\end{abstract}

Keywords: Babesia bovis, dairy cattle, epidemiology, force of infection, sero-prevalence, smallholder, Tanzania

\section{INTRODUCTION}

Cattle ticks of the genus Boophilus are the only vectors of Babesia bovis infection (Mahoney 1979), and of these, Boophilus microplus larvae have been singled out as the most efficient transmitting agents of Babesia bovis in areas were this infection exists (Riek 1966). The classic epidemiological model of

\footnotetext{
Veterinary Investigation Centre, Box 1068 Arusha, Tanzania. E-mail: emasw@yahoo.co.uk

2 Faculty of Veterinary Medicine, Sokoine University of Agriculture, Morogoro, Tanzania

3 Department of Veterinary Clinical Science and Animal Husbandry, University of Liverpool, UK

4 Department of Veterinary Pre-clinical Science, University of Liverpool, UK

5 Department of Veterinary Clinical Studies, University of Glasgow, Glasgow, UK

6 Department of Agriculture, University of Reading, UK

Accepted for publication 23 February 2004-Editor
}

babesiosis in cattle is based on the long lasting immunity induced by primary infection in calves up to 7-9 months old (Riek 1968) when they are naturally resistant to the clinical effects of primary infection. In those herds subjected to Babesia bovis infections are from 0.0005 to 0.005 infective bites/ head/day, are in endemic instability, while the risk is low, below or above those limit (Mahoney \& Ross 1972).

In this article we present the results of a cross-sectional study estimation of the prevalence of Babesia bovis antibodies in dairy cattle on the two contrasting and diverse smallholder dairying regions in Tanzania where Boophilus microplus is often thought not to exist (Lynen, Bakuname \& Sanka 1999). The objective were to quantify the occurrence of Babesia bovis through a serological survey, estimate the rate of infection of it and explore the possible relationship between the it and some animal/ farm level variables. 


\section{MATERIALS AND METHODS}

\section{Area and study population}

The study was carried out in five administrative districts of Tanga region and two in the Iringa region of Tanzania. Tanga region is situated on the North Eastern corner of Tanzania lying between longitude 36 and $38 \mathrm{E}$ and latitude 4 and $6 \mathrm{~S}$. The region has heterogeneous physical and climatic features varying from hot, humid coastal lowlands in the east to the cool Usambara Mountains in the north and semiarid plain in the southwest. There are two rainy seasons, the long rains occurring between March and May and the short rains occurring between September and November. Rainfall varies widely from 500 $\mathrm{mm}$ in semi-arid areas to $1400 \mathrm{~mm}$ in coastal areas and up to $2000 \mathrm{~mm}$ in some inland mountain areas. Daytime temperatures vary from $23-28{ }^{\circ} \mathrm{C}$ during the cool season (May to September) to $30-33^{\circ} \mathrm{C}$ during the hot season (December to March).

Iringa region is one of three in the Southern highland zone of Tanzania and lies between latitude 7 and $8 \mathrm{~S}$ and longitude 35 and $36 \mathrm{E}$. The region lies between 1340 and $2090 \mathrm{~m}$ above sea level. Rainfall is annually bimodal and ranges between 600 and $1600 \mathrm{~mm}$ per annum, with most rain falling between March and June and occasional light rain between August and September. In both regions, type of cattle kept includes Bos taurus breed (Friesian, Ayrshire, Jersey, Simmental) and crosses of these breeds with Bos indicus breeds (Tanzania shorthorn zebu, Boran and Sahiwal).

\section{Study design}

A sample size of farms and animals was estimated using Epi-Info version 6.04b (CDC, Atlanta, USA) in order to provide $80 \%$ power, with a confidence of $\alpha=0.05$, to estimate disease prevalence and detect associations between dependent and independent variables (Gitau, McDermott, Walter-Toews, Lissemore, Osumo \& Muruki 1994; French \& Tyrer 1997). The farms in each study region were randomly (EpiInfo version 6.04b) selected in October 1998, from a sampling frame of 3001 and 500 (in Tanga and in Iringa, respectively) using the databases of the Tanga and Iringa Dairy Development Projects. The Dutch and Swiss governments have been supporting dairy schemes in Tanga and Iringa regions, respectively. Over the last 15 years (1983-1998) of support, huge data bases have been generated.

As the antibody prevalence was not known a priori, a $50 \%$ prevalence was assumed when calculating the total number of farms required for the study, with a $10 \%$ allowable error. The farms in both study sites were estimated (on previous experience) to have an average of three to four dairy stock of any age, breed or sex. A farm sample size of 200 in each study region was considered necessary to provide between 600 and 800 animals for the study and to allow for a "design effect" of 2.0. Farms having more than ten animals were excluded from the selection process because such herds are not considered as "smallholder" enterprises (Tanga Dairy Development Programme 1999).

\section{Questionnaire design and administration}

One person in each region collected most farmlevel and some animal-level data using a structured questionnaire, which was completed by the smallholder on all the selected farms on a single visit. The questionnaire was designed to comprise mostly closed ended (categorical) questions to ease data processing, minimize variation and improve precision of responses (Thrusfield 2000). Questionnaire administration and collection of data from animals were carried out by two separate teams, during the period of January to April 1999, in the two regions. Although comparisons are made between the two regions, the data were not combined for analyses to allow any unexplained variation due to variations in the precise way that data were collected to be estimated.

The information gathered concerned farm and animal events that had occurred during 1998 and included cattle location, source (homebred or brought-in), mode of acquisition of dairy stock, sex, level of exotic blood (Filial generation), breed codes, age and housing practices, as well as whether or not a system of zero-grazing was practised of if the cattle had been allowed to graze on pastures in the 3 months prior to sampling. The detailed variables studied have been described by Swai (2002). The responses to many of these questions were investigated as explanatory variables in the analyses of sero-conversion to Babesia bovis.

\section{Collection of sera and their analysis}

During the visit to each farm, blood samples were collected by jugular venipuncture into $10 \mathrm{~m} \ell$ "Vacutainer" tubes (Becton Dickson, UK) from all animals on the farm. These were labelled and transported in a refrigerated cool box to local laboratories where aliquots of sera were obtained by centrifugation at $3000 \mathrm{~g}$ for $20 \mathrm{~min}$ after which they were then stored 
at $-20^{\circ} \mathrm{C}$ at Sokoine University of Agriculture (SUA) prior to dispatch in refrigerated containers to the International Livestock Research Institute (ILRI) in Nairobi, Kenya where they were subjected to indirect enzyme-linked immunosorbent assay (ELISA) in order to evaluate the level of antibodies to Babesia bovis (Katende, Goddeeris, Nkonge, Morzaria \& Musoke 1990; Katende,Toye, Skilton, Nene, Morzaria \& Musoke 1998). The ELISA has shown a sensitivity of $99 \%$ and a specificity of $98 \%$ (Katende et al. 1998). The results were expressed as percent positivity (PP) values of optical densities (Wright, Nilsson, Van Rooij, Lelenta \& Jeggo 1993), relative to that of a strongly positive control serum. Each test serum sample was analysed in duplicate and that of the control sera in triplicate. The threshold level of PP for positivity was $25 \%$ for Babesia bovis.

\section{Statistical methods}

Descriptive statistics for the animal- and farm-level explanatory variables examined in the study were developed using Epi-Info, version 6.04d. The relationships between explanatory variables and outcome response (sero-conversion to Babesia bovis) were investigated in two steps by logistic regression (using Egret for Windows version 2.0, Seattle, USA) with "farm" as a random effect because animals on one farm may not have been statistically independent of one another (Kristula, Curtis, Galligan \& Bartholomew 1992). In the first step, the relationships between each explanatory and outcome variable were individually investigated. In the second step, any variables that were significantly associated at the $P<0.25$ level were included in multivariable models producing, by forwards and backwards substitution and elimination, the most parsimonious models in which all explanatory variables remained significant at the $P<0.05$ level. The criteria for inclusion and exclusion were a change of in deviance significant at the $5 \%$ level according to the maximum likelihood ratio test-Chi square distribution.

Forces of infection were estimated from age seroprevalence profiles using Maximum Likelihood Methods (MLM) in Excel (Microsoft, USA) with solver add-in (Thrusfield 2000). Assuming a stable population size and age structure and a constant force of infection across all age groups, the log likelihood was derived using the following formula:

Loglikelihood $L=\sum_{i=1}^{\mathrm{a}} R_{i} \ell n e^{-\lambda i}+\left(N_{i}-R_{i}\right) \ln \left(1-e^{-\lambda i}\right)$ where $R_{i}=$ number of sero-positive in group $i, N_{i}=$ number tested in age group $i$ and $\lambda=$ the force of infection

\section{RESULTS}

\section{Farm participation}

All selected 200 farms from each of Tanga and Iringa regions were visited and farmers interviewed during the period of January 1999 to April 1999 (a $100 \%$ response rate). In Tanga, a total of 697 animals kept on $185(92.5 \%)$ farms were examined. Fifteen farms $(7.5 \%)$ had no animals during the actual survey period. In Iringa, a total of 698 animals from $195(97.5 \%)$ farms were examined. Three farms $(1.5 \%)$ had no animals and two farms $(1 \%)$ could not be sampled because the owner could not be traced. The number of animals examined per herd was 3 ranged from 1 to 9 animals. The distribution of cattle amongst categories of each variable investigated is summarised in Table 1.

\section{Serological responses to Babesia bovis}

The crude sero-prevalence of antibodies to Babesia bovis was $6 \%(4.7,8.6)$ and $12 \%(9.6,14.7)$ for Tanga and Iringa, respectively (Table 2 ).

The estimated force of infection was 0.04 and 0.06 per animal years-risk for Tanga and Iringa, respectively. The graphical forces of infection are shown in Fig.1 and 2. The estimated force of infection was slightly higher in Iringa than in Tanga.

The results of the final logistic regression model are detailed in Tables 3 and 4.

In both Tanga and Iringa regions sero-prevalence was significantly greater in grazed animals than in zero-grazed animals. In Iringa region animals located in Iringa urban district were significantly more likely to be sero-positive for Babesia bovis than animals on farms in Iringa rural district $(\mathrm{OR}=5.83, P$ $=0.010)$. In both regions cattle brought onto the farms were significantly more likely to be sero-positive than animals born on-farm $(\mathrm{OR}=2.43, P=$ 0.035 and $\mathrm{OR}=3.1, P=0.016$, respectively for Iringa and Tanga regions).

\section{DISCUSSION}

The prevalence of Babesia bovis infection as reflected by ELISA appears to be comparatively higher in Iringa (12\%) than in Tanga (6\%). However, the 
TABLE 1 The proportions of cattle in each category of each variable investigated during the study

\begin{tabular}{|c|c|c|c|c|c|}
\hline \multirow{2}{*}{ Variable } & \multirow{2}{*}{ Categories } & \multicolumn{4}{|c|}{ No. of animals (\%) } \\
\hline & & \multicolumn{2}{|c|}{ Iringa } & \multicolumn{2}{|c|}{ Tanga } \\
\hline \multicolumn{6}{|l|}{ Animal-level variables } \\
\hline Sex & $\begin{array}{l}\text { Male } \\
\text { Female }\end{array}$ & $\begin{array}{l}182 \\
516\end{array}$ & $\begin{array}{l}(26) \\
(74)\end{array}$ & $\begin{array}{l}146 \\
551\end{array}$ & $\begin{array}{l}(21) \\
(79)\end{array}$ \\
\hline Source of animal & $\begin{array}{l}\text { Homebred } \\
\text { Brought-in }\end{array}$ & $\begin{array}{l}406 \\
292\end{array}$ & $\begin{array}{l}(58) \\
(41)\end{array}$ & $\begin{array}{l}436 \\
261\end{array}$ & $\begin{array}{l}(63) \\
(37)\end{array}$ \\
\hline Filial generation & $\begin{array}{l}\text { F1 } \\
\text { F2 } \\
\text { F3 }\end{array}$ & $\begin{array}{r}350 \\
347 \\
1\end{array}$ & $\begin{array}{r}(50) \\
(49) \\
(0.1)\end{array}$ & $\begin{array}{r}217 \\
459 \\
21\end{array}$ & $\begin{array}{r}(31) \\
(66) \\
(3)\end{array}$ \\
\hline Breed codes & $\begin{array}{l}\text { Ayrshire cross } \\
\text { Friesian cross } \\
\text { Jersey cross } \\
\text { Simmental cross } \\
\text { Sahiwal cross } \\
\text { TSHZ cross } \\
\text { Boran cross }\end{array}$ & $\begin{array}{r}403 \\
305 \\
1 \\
0 \\
0 \\
150 \\
549\end{array}$ & $\begin{array}{l}(58) \\
(44) \\
(0.1) \\
\\
(22) \\
(78)\end{array}$ & $\begin{array}{r}169 \\
604 \\
12 \\
5 \\
12 \\
541 \\
121\end{array}$ & $\begin{array}{r}(24) \\
(86) \\
(2) \\
(1) \\
(2) \\
(77) \\
(17)\end{array}$ \\
\hline Age & $\begin{array}{l}<3 \text { years } \\
3 \text { to }<6 \text { years } \\
>6 \text { years }\end{array}$ & $\begin{array}{r}440 \\
165 \\
93\end{array}$ & $\begin{array}{l}(63) \\
(24) \\
(13)\end{array}$ & $\begin{array}{r}396 \\
214 \\
87\end{array}$ & $\begin{array}{l}(57) \\
(31) \\
(12)\end{array}$ \\
\hline Grazing history in 1998 & $\begin{array}{l}\text { Zero grazing } \\
\text { Semi/free grazing }\end{array}$ & $\begin{array}{l}489 \\
209\end{array}$ & $\begin{array}{l}(70) \\
(30)\end{array}$ & $\begin{array}{r}631 \\
66\end{array}$ & $\begin{array}{l}(90) \\
(10)\end{array}$ \\
\hline Farm-level variables & & & & & \\
\hline Farm classification & $\begin{array}{l}\text { Peri-urban } \\
\text { Urban } \\
\text { Rural }\end{array}$ & $\begin{array}{l}109 \\
391 \\
198\end{array}$ & $\begin{array}{l}(16) \\
(56) \\
(28)\end{array}$ & $\begin{array}{l}117 \\
318 \\
262\end{array}$ & $\begin{array}{l}(17) \\
(46) \\
(37)\end{array}$ \\
\hline District (Iringa) & $\begin{array}{l}\text { Iringa urban } \\
\text { Iringa rural }\end{array}$ & $\begin{array}{l}461 \\
237\end{array}$ & $\begin{array}{l}(66) \\
(34)\end{array}$ & NA & \\
\hline District (Tanga) & $\begin{array}{l}\text { Tanga } \\
\text { Muheza } \\
\text { Pangani } \\
\text { Korogwe } \\
\text { Lushoto }\end{array}$ & NA & & $\begin{array}{r}341 \\
185 \\
26 \\
64 \\
81\end{array}$ & $\begin{array}{r}(48.8) \\
(26.5) \\
(4) \\
(9) \\
(12)\end{array}$ \\
\hline Mode of acquisition & $\begin{array}{l}\text { Bought cash } \\
\text { Credit (HIT) } \\
\text { Others (gift) }\end{array}$ & $\begin{array}{l}471 \\
117 \\
110\end{array}$ & $\begin{array}{l}(67) \\
(17) \\
(16)\end{array}$ & $\begin{array}{r}268 \\
356 \\
73\end{array}$ & $\begin{array}{l}(38) \\
(51) \\
(11)\end{array}$ \\
\hline
\end{tabular}

TABLE 2 The prevalence (with +/- $95 \%$ confidence intervals) of cattle sero-positive for Babesia bovis in the study regions (January to April 1999)

\begin{tabular}{|l|l|l|l|l|l|}
\hline \multirow{2}{*}{ Region } & \multirow{2}{*}{ No tested } & No positive & \multirow{2}{*}{$\begin{array}{l}\text { Prevalence } \\
(\%)\end{array}$} & \multicolumn{2}{|l|}{$95 \% \mathrm{Cl}$} \\
\cline { 4 - 6 } & & & Lower & Upper \\
\hline $\begin{array}{l}\text { Tanga } \\
\text { Iringa }\end{array}$ & 697 & 42 & 6 & 4.7 & 8.6 \\
\hline
\end{tabular}


E.S. SWAl et al.

TABLE 3 Final logistic binomial multiple regression for sero-prevalence of Babesia bovis in dairy cattle, Tanga, Tanzania (January to April 1999)

\begin{tabular}{|l|l|l|l|l|l|}
\hline Factor & $\beta(\mathrm{SE})$ & OR & $\begin{array}{c}\text { Lower to upper } \\
95 \% \mathrm{Cl}\end{array}$ & Wald $P$ & Likelihood ratio $P$ \\
\hline Constant & $-4.33(0.56)$ & & & & \\
Grazing vs zero grazing & $1.84(0.57)$ & 6.34 & $2.05-19.56$ & 0.001 & $<0.001$ \\
Brought vs Homebred & $1.14(0.47)$ & 3.15 & $1.23-8.03$ & 0.016 & $<0.001$ \\
Random term & $1.44(0.38)$ & & & & \\
\hline
\end{tabular}

TABLE 4 Final logistic binomial multiple regression for sero-prevalence of Babesia bovis in dairy cattle, Iringa, Tanzania (January to April 1999)

\begin{tabular}{|c|c|c|c|c|c|}
\hline Factor & $\beta(\mathrm{SE})$ & OR & $\begin{array}{l}\text { Lower to upper } \\
95 \% \mathrm{Cl}\end{array}$ & Wald $P$ & Likelihood ratio $P$ \\
\hline Constant & $-5.57 \quad(0.82)$ & & & & \\
\hline Grazing vs zero grazing & 1.29 (0.48) & 3.65 & $1.40-9.49$ & 0.007 & $<0.001$ \\
\hline Brought vs Homebred & $0.88 \quad(0.42)$ & 2.43 & $1.06-5.56$ & 0.035 & $<0.001$ \\
\hline Iringa Urban vs Iringa Rural & $1.76(0.68)$ & 3.83 & $1.51-22.53$ & 0.010 & 0.032 \\
\hline Age centred & $0.008(0.006)$ & & & 0.062 & \\
\hline Random term & $2.06 \quad(0.40)$ & & & & \\
\hline
\end{tabular}

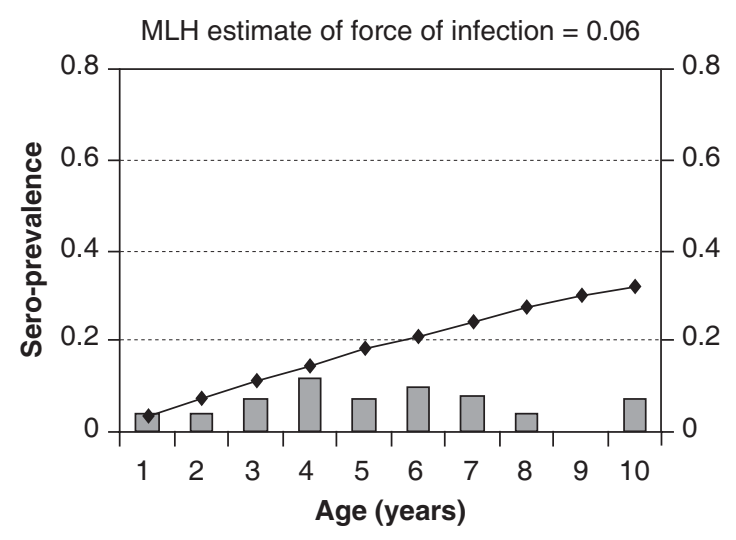

FIG. 1 Force of infection estimates for Babesia bovis infection in dairy cattle-Iringa, Tanzania (January to April 1999)

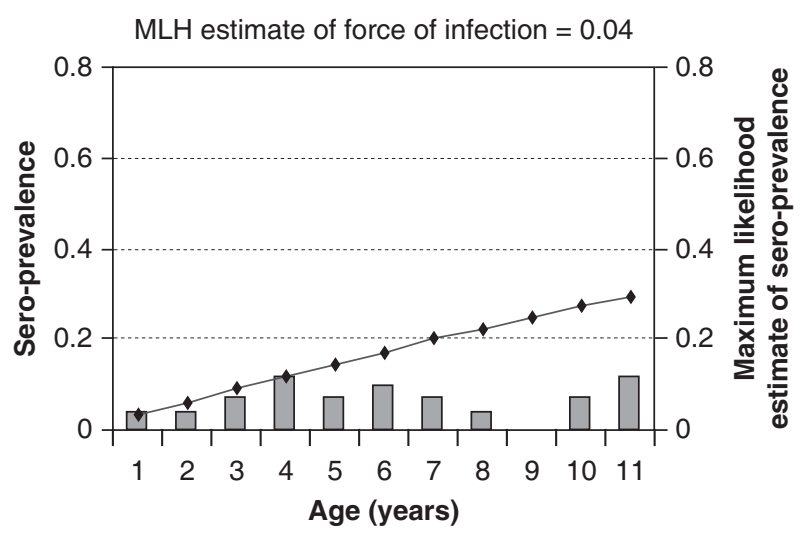

FIG. 2 Force of infection estimates for Babesia bovis infection in dairy cattle-Tanga, Tanzania (January to April 1999)

district where the Babesia infection is known to exist. The low serological prevalence for Babesia bovis infection may be due to its poor infectivity for Babesia (Mahoney \& Mirre 1971) and subsequently the occurrence of lower inoculation rates in susceptible cattle (Mahoney 1979). The lower observed inoculation rates (force of infection), in the light of these findings, may predict an enhanced tick resistance (Mahoney 1979) or a genetically based immunity to Babesia bovis characteristic of zebu crosses, which results in low inoculation rates of this Babesia parasite.

As in other studies, in both Tanga and Iringa regions, a history of recent grazing prior to sampling was ic instability" prevails and that a similar distribution of the vector ticks (Boophilus spp.) occurs in the 
associated with a significantly higher likelihood of an animal being sero-positive to Babesia bovis infection, compared to zero-grazed animals (Maloo et al. 2001).

Sero-prevalence varied with the mode of acquisition of the animals. Accounting for age, brought-in animals were more likely to be sero-positive for Babesia bovis than were homebred animals. This would be consistent with the fact that most dairy stock available for sale in local markets are pregnant heifers from specialized large-scale crossbreeding ranches where they are mostly grazed rather than housed (Swai 2002).

Allowing for variations in sero-prevalence related to age and management factors, such as grazing, geographic variation in sero-prevalence of Babesia bovis infection was also determined. This variation was more conspicuous in the Iringa study region with the odds of infection being three fold for cattle situated in Iringa urban areas when compared to that in the cattle in the Iringa rural district. This implies that there must be geographical variations in either the density of tick vectors or the prevalence of Babesia bovis infection in host-seeking ticks, or both. Variations in sero-prevalence may partly be owing to cattle immune responses (Mahoney 1979). Geographic variation in sero-prevalence was more uniform and generally higher in the Iringa region. Babesiosis has not been reported to be a major clinical problem in both study regions (TDDP 1999; Southern Highland Dairy Development Programme 1995) but there might be underestimations of clinical babesiosis in these regions.

A diagnosis of bracken poisoning is frequently made by farmers and extension workers when cattle show clinical signs of "red water" (haemoglobinuria or haematuria) and in the light of the findings in this survey, some or many of these cases may, in fact, be misdiagnosed cases of babesiosis.

An increased trend of sero-positivity associated with age was evident in this study. These findings are consistent with previous reports (Hugh-Jones, Busch \& Jones 1988) which showed young animals to be more resistant to primary infections.

We decided a priori to allow for intraherd correlation in the analysis by incorporating "farm" as a randomeffect term in all models. However in common with similar studies (Gitau et al. 1994), there was little evidence of clustering at the level of farm, probably owing to the small number of animals per farm (McDermott \& Schukken 1994)

\section{CONCLUSION}

The results of this study can be summarized as follows:

- Sero-prevalence of antibodies to Babesia bovis was low in smallholder dairy cattle in the study regions, most likely due to zero-grazing management, but there was evidence of a wide distribution in both the study regions.

- Consistent with this the force of infection varied geographically. It was, however, comparatively low and the likelihood of a bovine encountering the infection increased significantly with age.

- Farmer reporting of grazing significantly increased the likelihood of contact of cattle with infective ticks.

- The source of animals, particularly recently purchased animals, may be more likely to have encountered and recovered from Babesia bovis infection.

\section{ACKNOWLEDGEMENTS}

We thank the Government of UK through DFID NRRD Animal Health Research Programme for financing this work which formed part of a study for the Ph.D. degree on the epidemiology of tick-borne diseases in small-scale farming systems in Tanzania. The generous cooperation of smallholder farmers, extension staff and laboratory personnel at ILRI/SUA is also acknowledged. Our thanks are extended to the Director of Veterinary Service, Tanzania for permission to publish this work.

\section{REFERENCES}

CYTEL SOFTWARE CORPORATION 1999. Statistics and Epidemiology Research Corporation, ver. 2.0. Seattle, USA.

EPI-INFO 1996. Epi-info. Centre for Disease Control, version 6.04d, Atlanta, USA and Geneva, Switzerland.

FRENCH, N.P. \& TYRER, J. 1997. Birth and death of cattle on small scale dairy farms in Zimbabwe. Society of Veterinary Epidemiology and Preventive Medicine, Chester. Poster presentation.

GITAU, G.K., MCDERMOTT, J.J., WALTNER-TOEWS, D., LISSEMORE, K.D., OSUMO, J.M. \& MURIUKI, D. 1994. Factors influencing calf morbidity and mortality in smallholder dairy farms in Kiambu District, Kenya. Preventive Veterinary Medicine, 21:167-177.

HUGH-JONES, M.E., BUSCH, R.C. \& JONES, F. 1988. Seroprevalence survey of Anaplasma marginale card-test reactors in Louisiana, USA, cattle. Preventive Veterinary Medicine, 6:143-153. 
KATENDE, J.M., GODDEERIS, B.M., NKONGE, C.G., MORZARIA, S.P \& MUSOKE, A.J. 1990. Identification of a Theileria antigen for use in an antibody and antigen detection ELISA. Parasite Immunology, 12:419-433.

KATENDE, J.M., TOYE, P., SKILTON, R.A., NENE, V., MORZARIA, S.P \& MUSOKE, A.J. 1998. An ELISA for detection of $T$. parva antibodies using recombinant immunodominant molecule. Parasitology Research, 84:408-416.

KRISTULA, M.A., CURTIS, C.R., GALLIGAN, D.T \& BARTHOLOMEW, R.W. 1992. Use of a repeated measures logistic regression model to predict chronic mastitis in dairy cows. Preventive Veterinary Medicine, 14:57-68.

LYNEN, G., BAKUNAME, C. \& SANKA, P. 1999. Tick and TBD survey in Northern Regions of Tanzania. Proceedings of Tanzania Veterinary Association Conference, Arusha, December, 1999

MAHONEY, D.F. \& MIRRE, G.B. 1971. Annals of Tropical Medicine and Parasitology, 65:309-317.

MAHONEY, D.F. \& ROSS, D.R. 1972. Bovine babesiosis: Computer simulation of Babesia argentina rates in Bos taurus cattle. Annals of Tropical Medicine and Parasitology, 68: 385-392.

MAHONEY, D.F. 1979. Babesiosis in domestic animals, in Parasitic protozoa, Vol. IV, edited by J.P. Kreier. New York: Academic Press.

MALOO, S.H., THORPE, W., KIOO, G., NGUMI, P., ROWLAND, G.J. \& PERRY, B.D. 2001. Sero-prevalence of vector transmitted infections of small-holder dairy cattle in coastal Kenya. Preventive Veterinary Medicine, 52:1-16.

McDERMOTT, J.J \& SCHUKKEN, Y.H. 1994. A review of the methods used to adjust fro cluster effects in explanatory epi- demiological studies of animal populations. Preventive Veterinary Medicine, 18:155-173.

PEREZ, E., HERRERO, M.V., JIMENEZ, C., CARPENTER, T.E. \& BUENING, G.B. 1994. Epidemiology of bovine anaplasmosis and babesiosis in Costa Rica. Preventive Veterinary Medicine, 20:23-31.

RIEK, R.F. 1966. The life cycle of Babesia argentina in the tick vector Boophilus microplus. Australian Journal of Agricultural Research, 17:247-254

RIEK, R.F. 1968. Babesiosis, in Infection blood disease of man and animals, edited by D.F. Weinmann \& M. Ristic. New York: Academic Press.

SOUTHERN HIGHLAND DAIRY DEVELOPMENT PROGRAMME. 1995. Annual Progress Report, Iringa.

SWAI, E.S. 2002. Epidemiological studies of tick borne diseases in small scale dairy farming systems in Tanzania. Ph.D. thesis, University of Reading.

TANGA DAIRY DEVELOPMENT PROGRAMME 1999. Annual Progress Report, Tanga.

THRUSFIELD, M. 2000. Veterinary Epidemiology. UK, Blackwell Science

WOODFORD, J.S., JONES, T.W., RAE, P.F., BOID, R. \& BELLSAIKYI 1990. Sero-epidemiological studies of bovine babesiosis on Pemba Island, Tanzania. Veterinary Parasitology, 37:175-184.

WRIGHT, P.F., NILSSON, F., VAN ROOIJ, E.M.A., LELENTA, M. \& JEGGO, M.H. 1993. Standardisation and validation of enzyme linkage immunosorbent assay technique for detection of antibody in infectious disease diagnosis. Revue Scientifique Technique office international des Epizooties, 12: 435-450. 